\begin{tabular}{|c|} 
ISSN = 1980-993X - doi:10.4136/1980-993X \\
www.agro.unitau.br/ambi-agua \\
E-mail: ambi-agua@agro.unitau.br \\
Tel.: (12) 3625-4116
\end{tabular}

\title{
Escoamento superficial na bacia hidrográfica do Ribeirão Itaim (doi:10.4136/ambi-agua.19)
}

\author{
Luiz Sérgio Gonçalves Aguiar; Marcelo dos Santos Targa; \\ Getulio Teixeira Batista
}

\begin{abstract}
Programa de Pós-Graduação em Ciências Ambientais da Universidade de Taubaté
\end{abstract} E-mail: aguiar.agro@gmail.com; \{mtarga; getulio\}@agro.unitau.br

\section{RESUMO}

Este trabalho realizado, na bacia hidrográfica do ribeirão Itaim, município de Taubaté, $\mathrm{SP}$, visou estimar o escoamento superficial pelo método Curva-Número (CN) em área com cobertura vegetal de Brachiaria Decumbens, que é predominante na bacia. Valores do CN foram definidos em função do uso e cobertura do solo. O escoamento superficial (Q) foi estimado por três métodos: $1^{\circ}$ ) utilizaram-se-se valores de infiltração acumulada (IAc) obtidos no campo, considerados como Infiltração Potencial (S), os quais variaram de 15,37 mm a $51,88 \mathrm{~mm}$ com um valor médio de 23,46 mm. Com esses valores de infiltração e utilizando-se valores de precipitações máximas para Taubaté, SP, com tempo de duração de 3 horas: $\mathrm{P}=$ 54,4; 70,3; 80,8; 86,7; 90,9; 94,1 e 103,9 mm, respectivamente, para os tempos de retorno de $\operatorname{Tr}=2$, 5, 10, 15, 25, 50 e 100 anos, os seguintes valores de (Q) foram obtidos: 34,83; 49,33; 59,14; 64,71; 68,69; 71,73 e 81,10 mm, respectivamente; $2^{\circ}$ ) considerou-se a predominância de Pasto Sujo na bacia e utilizando-se o valor adimensional $C N=75$, obteve-se $S=84,7 \mathrm{~mm}$ e chegou-se aos valores de (Q) que variaram de 11 a $44 \mathrm{~mm} ; 3^{\circ}$ ) considerou-se o valor ponderado para todas as classes de uso da bacia, $\mathrm{CN}_{\text {ponderado }}=66,57$, e obteve-se um valor mais elevado para infiltração potencial, $\mathrm{S}=127 \mathrm{~mm}$. Conseqüentemente, os resultados dos valores de (Q) foram mais baixos e corresponderam a 5,33; 11,64; 16,72; 19,83; 22,16; 23,98 e 29,83 mm, respectivamente. Dessa forma, concluiu-se que o método CN (tanto para a classe predominante quanto para o ponderado) subestimou o escoamento superficial na área estudada. Entretanto, é possível sua utilização desde que se promovam os ajustes para as situações locais com base em medidas prévias de infiltração em campo.

Palavras-chave: escoamento superficial; infiltração; curva-número; infiltrômetro de anéis; bacia hidrográfica.

\section{Surface runoff in the Itaim Watershed}

\section{ABSTRACT}

This paper describes a work done in the Itaim watershed at Taubaté, SP, and had the objective of estimating the surface runoff based on the Curve-Number (CN) method in area with vegetation cover of grassland (Brachiaria Decumbens), that prevails in this watershed. The surface runoff was estimated using three different methods: $1^{\text {st }}$ ) values of accumulated Infiltration (IAc) obtained in the field were used, considered as the Potential Infiltration (S), which varied from $15.37 \mathrm{~mm}$ to $51.88 \mathrm{~mm}$ with an average value of $23.46 \mathrm{~mm}$. With those measured infiltration rates and using the maximum precipitation values for Taubaté, SP, with duration time of 3 hours: $\mathrm{P}=54.4$; 70.3; 80.8; 86.7; 90.9; 94.1 and $103.9 \mathrm{~mm}$, respectively, for the return times, $\operatorname{Tr}=2,5,10,15,25,50$ and 100 years, the following values of surface runoff were generated: 34.83; 49.33; 59.14; 64.71; 68.69; 71.73 and $81.10 \mathrm{~mm}$, respectively; In the $2^{\text {nd }}$ method it was considered that the prevailing vegetation cover of the watershed was Dirty Pasture (Pasture with regrowth of natural vegetation) and therefore, a value of $\mathrm{CN}=75$ 
was used and generated a potential infiltration, $\mathrm{S}=84,7 \mathrm{~mm}$ and resulted in surface runoff values that varied from 11 to $44 \mathrm{~mm}$; In the $3^{\text {rd }}$ method, the value of CN was considered equal to 66.57. This value was calculated weighting the contribution of all land use cover classes of the watershed, and as a result a higher value of potential infiltration, $\mathrm{S}=127 \mathrm{~mm}$, was obtained. Consequently, the surface runoff values were $5.33 ; 11.64 ; 16.72 ; 19.83 ; 22.16$; 23.98 and $29.83 \mathrm{~mm}$, respectively. Therefore, the comparison with the results obtained by the two Curve-Number methods (conventional and weighted) allowed the conclusion that the Curve-Number method applied in a conventional way underestimated the surface runoff in the studied area. However, results indicate that it is possible to use this method for surface runoff estimates as long as adjustments based on potential infiltration obtained in field be are available for local situations.

Keywords: surface runoff; infiltration; curve-number; infiltrometer rings; hydrographic basin.

\section{INTRODUÇÃO}

A dinâmica de uso e ocupação do solo em bacias hidrográficas exige estudos para a compreensão dos diversos impactos provocados pela ação antrópica e estratégias adequadas para a conservação dos recursos naturais nessas áreas. Os principais impactos ocasionados por modificações no uso e cobertura do solo em bacias hidrográficas são: a redução da capacidade de infiltração, o aumento do escoamento superficial e erosão, a sedimentação dos cursos d'água, a diminuição da profundidade do leito dos cursos d'água e, conseqüentemente, o aumento de cheias e inundações (Grove et al., 1998; Centurion et al, 2001; Wendland, 2001).

Para Grove et al (1998), uma das técnicas mais amplamente utilizada para estimar o escoamento superficial é o método Curva-Número ou CN desenvolvido pelo Serviço de Conservação do Solo (SCS - USDA), atualmente denominado de Serviço de Conservação dos Recursos Naturais (NRCS-USDA). O método é empírico e baseado em um conjunto de relações entre precipitação, condições de superfície do solo e escoamento.

Segundo Braga Jr. e Conejo (1983), é importante que o escoamento superficial não seja analisado de maneira isolada e, sim, com clara compreensão de que os processos de infiltração e escoamento ocorrem simultaneamente.

Para Secco et al. (2005), o estudo dos atributos físicos do solo, tais como densidade e espaço poroso, podem ser utilizados como indicadores da qualidade do solo e refletir o manejo a que o solo está sendo submetido, o que facilita o entendimento desses processos.

Centurion et al. (2001) afirmam que a alteração de ecossistemas naturais acontece devido à implementação de atividades voltadas para fins industriais ou de produção de alimentos, o que quase sempre promove uso e manejo inadequado dos solos. Assim, a retirada da cobertura vegetal original e sua substituição por culturas propiciam o rompimento do equilíbrio entre o solo e o meio, interferindo nas condições químicas, físicas e biológicas, o que acentua os efeitos erosivos nessas áreas.

A bacia do Ribeirão Itaim sofreu, nos últimos anos, um aumento significativo da ocupação urbana e predomínio das pastagens em sua paisagem, refletindo em diminuição da infiltrabilidade da água e no aumento do escoamento superficial (Aguiar, 2004). Nesse sentido, deve-se considerar o grau de preservação da bacia e a relação existente entre a precipitação e o escoamento superficial, parâmetros importantes no estudo de bacias hidrográficas.

Segundo Wendland (2001), quando se estuda a precipitação intensa, contínua e persistente, tem-se uma boa análise sobre o impacto significativo exercido pelos recursos superficiais da água do solo, não somente de forma imediata, mas também a médio e longo 
prazo, o que denota a necessidade de informações que podem ser valorosas para o gerenciamento dos recursos hídricos. Esse tipo de informação pode ser obtida com mensurações da taxa de infiltração de água no solo.

Para Diamond e Shanley (2003), a avaliação do escoamento superficial tem adquirido importância crescente, devido aos perigos de erosão e poluição associados. Assim, determinações precisas das taxas de infiltração constituem um fator importante na previsão confiável do escoamento superficial.

O aumento da atividade humana também influi na disponibilidade hídrica das bacias, assim, é fator importante a ser analisado, pois tem provocado importantes alterações e conseqüentes impactos sobre esses ecossistemas, o que demanda planejamento ambiental, que deve contemplar não apenas os ambientes criados e alterados pelos seres humanos, mas também o ambiente natural ao seu redor (Rocha, 2000). Esse autor ressalta que a bacia hidrográfica é uma unidade natural de planejamento ambiental, o que permite, que seja o local onde esses estudos possam ser melhor avaliados.

De acordo com Tripathi et al (2003), o estudo intensivo das bacias individuais e diversificadas torna-se necessário para possibilitar o desenvolvimento de planos de administração a serem desenvolvidos e também para aplicar os resultados de uma bacia para outra com características similares. Assim, os estudos hidrológicos desenvolvidos na bacia do Ribeirão Itaim podem contribuir para nortear ações de recuperação e sustentabilidade ambiental na região, ampliando o conhecimento sobre as taxas de infiltração da água e do escoamento superficial e suas conseqüências em bacias com características similares.

Smemoe et al. (2004), ao desenvolverem o modelo de precipitação/escoamento para uma área de drenagem, observaram que uma das relações mais importantes a considerar é a determinação da quantidade de chuva que é convertida em escoamento. Assim, outros métodos têm sido idealizados, para determinar a quantidade de precipitação convertida em escoamento. Esses autores afirmam que o método Curva-Número (CN) fornece uma boa visão de como o escoamento na bacia é determinado a partir dos dados da precipitação. Muitas dessas suposições utilizadas pelo método $\mathrm{CN}$ são baseadas em observações empíricas da precipitação e do escoamento em áreas específicas. Contudo, o método do Curva Número é resultante de longa data de investigação para a estimativa do escoamento direto produzido das precipitações máximas e contou com esforços de pesquisadores (Sherman, 1942; Mockus, 1949; Andrews, 1954; Ogrosky, 1956 apud NRCS, 2004).

O objetivo deste trabalho foi o de determinar valores da taxa de infiltração de água em situações de campo, bem como fazer estimativas confiáveis do escoamento superficial e comparar os resultados com o método curva-número (convencional e ponderado) para essas estimativas. A Bacia do Ribeirão Itaim, no município de Taubaté, SP, foi escolhida para a realização destes estudos, em virtude de ser uma reserva estratégica de água para o município de Taubaté, pois é uma bacia contribuinte do Rio Una, que no passado foi responsável pelo fornecimento de mais de $70 \%$ da água para abastecimento de Taubaté.

\section{MATERIAL E MÉTODOS}

O trabalho foi conduzido na bacia hidrográfica do ribeirão Itaim que possui área de 57,7 $\mathrm{km}^{2}$ (Sbruzzi, 2004). A área de estudo tem cobertura vegetal predominante de pastagem (Brachiaria decumbens) e localiza-se na Fazenda Experimental do Departamento de Ciências Agrárias da Universidade de Taubaté (UNITAU), no município de Taubaté, SP.

O solo da área de estudo é classificado como Latossolo Vermelho Amarelo textura areno-argilosa (EMBRAPA, 1997); o relevo é ondulado e a altitude média é de 580 metros. O clima da região é CWA, segundo a classificação de Köppen, e caracteriza-se por ser quente e 
úmido no verão e frio e seco no inverno A fórmula climática de Taubaté utilizando a classificação de Thornthwaite, é $\mathrm{B}_{1} \mathrm{rB}_{3} \mathrm{a}^{\prime}$, que representa clima úmido com pequena ou nula deficiência de água, mesotérmico, com evapotranspiração potencial anual de $964 \mathrm{~mm}$ e concentração de evapotranspiração potencial no verão de 33\% (Fisch, 1999).

Neste trabalho, utilizou-se o método Curva-Número ou CN desenvolvido pelo NRCS USDA, que é considerado o método mais utilizado para a estimativa do escoamento superficial em bacias hidrográficas (Machado, 2002). O método é baseado nas seguintes equações:

$$
\begin{aligned}
& Q=\frac{(P-0,2 S)^{2}}{(P+0,8 S)} \\
& S=\frac{25400}{C N}-254
\end{aligned}
$$

em que:

Q: escoamento superficial (mm);

P: Precipitação Máxima em dado Período de Retorno (mm);

S: Infiltração Potencial (mm);

CN: Curva Número, valor adimensional tabelado.

Martinez Junior e Magni (1999) indicaram, para um tempo de duração de 3 horas em Taubaté, a ocorrência de precipitações máximas de 54,4; 70,3; 80,8; 86,7; 90,9; 94,1 e 103,9 $\mathrm{mm}$, respectivamente, para os tempos de retorno de 2, 5, 10, 15, 25, 50 e 100 anos, respectivamente.

A estimativa do escoamento superficial foi feita utilizando-se três métodos distintos:

\section{$\left.1^{\circ}\right)$ Medidas de campo}

Segundo Maheshawari (1996), os infiltrômetros de anéis são comumente utilizados para mensurações in-situ das características da infiltração. Os infiltrômetros podem ser de anel simples ou duplo, sendo o de anel duplo o preferido, porque o anel externo ajuda a prevenir o fluxo lateral, diminuindo o erro da leitura.

Mediu-se a infiltração acumulada (IAc) no campo pelo método de anéis concêntricos, considerando o tempo de infiltração igual ao tempo de concentração da Bacia de 3 horas (Moreira, 2005) que foi considerada como Infiltração Potencial (S) e, posteriormente, aplicada à Equação (1) para o cálculo do escoamento superficial no ponto amostrado. O método do Infiltrômetro de Anéis Concêntricos (IANC) foi adotado para a determinação da infiltração da água, seguindo-se a metodologia descrita em Bernardo (1982). Os testes de infiltração de água no solo, visando determinar a infiltração acumulada (IAc) e a velocidade de infiltração básica (VIB), foram feitos em 5 pontos da Bacia com cobertura vegetal do tipo Pasto Sujo (Figura 1), os quais foram identificados pelas coordenadas geográficas obtidas por meio de receptor GPS, conforme mostra a Tabela 1. Em cada ponto, foram feitas 4 medidas da densidade do solo (ds) e da porosidade total (p) conforme o método de Bouyoucos (EMBRAPA, 1997). 
Tabela 1. Coordenadas Geográficas, em UTM, dos pontos onde foram realizados os testes de infiltração (Zona 23 - Hemisfério Sul DATUM WGS 84).

\begin{tabular}{ccc}
\hline Cobertura de Pasto Sujo & E (m) & N (m) \\
\hline Ponto 1 & 446.996 & 7.452 .890 \\
Ponto 2 & 447.015 & 7.452 .818 \\
Ponto 3 & 446.950 & 7.452 .846 \\
Ponto 4 & 446.987 & 7.452 .868 \\
Ponto 5 & 446.964 & 7.452 .885 \\
\hline
\end{tabular}

\section{$2^{\circ}$ ) Método CN para cobertura predominante (Pasto Sujo)}

Considerou-se que a cobertura vegetal da bacia era totalmente constituída de Pasto Sujo, em boa condição hidrológica (Aguiar et al., 2003) e solo pertencente ao grupo C, cujo valor de CN é igual a 75, segundo Setzer e Porto (1979), para o cálculo da infiltração potencial (S), o qual foi, posteriormente, aplicado à Eq. 1 para o cálculo do escoamento superficial. O solo estava na condição II de umidade (chuva dos últimos 5 dias antecedentes entre 15 e $40 \mathrm{~mm}$ ).

\section{$\left.3^{\circ}\right)$ Método CN Ponderado}

Consideraram-se as diversas classes de cobertura vegetal da bacia extraídas de Aguiar et al. (2003) para a definição do valor do $\mathrm{CN}_{\text {ponderado }}$ (Tabela 2) para o cálculo da infiltração potencial (S), posteriormente utilizado na Eq. 1 para o cálculo do escoamento superficial.

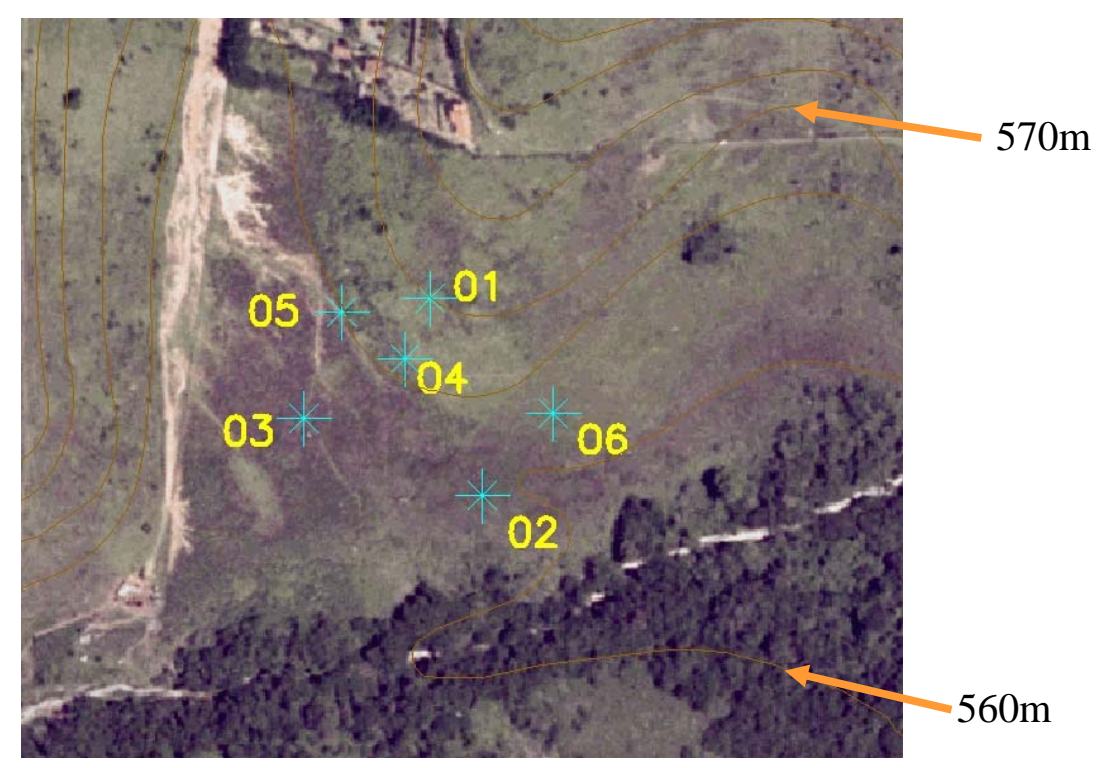

Figura 1. Pontos onde foram realizados os testes de infiltração próximo ao ribeirão Itaim. 


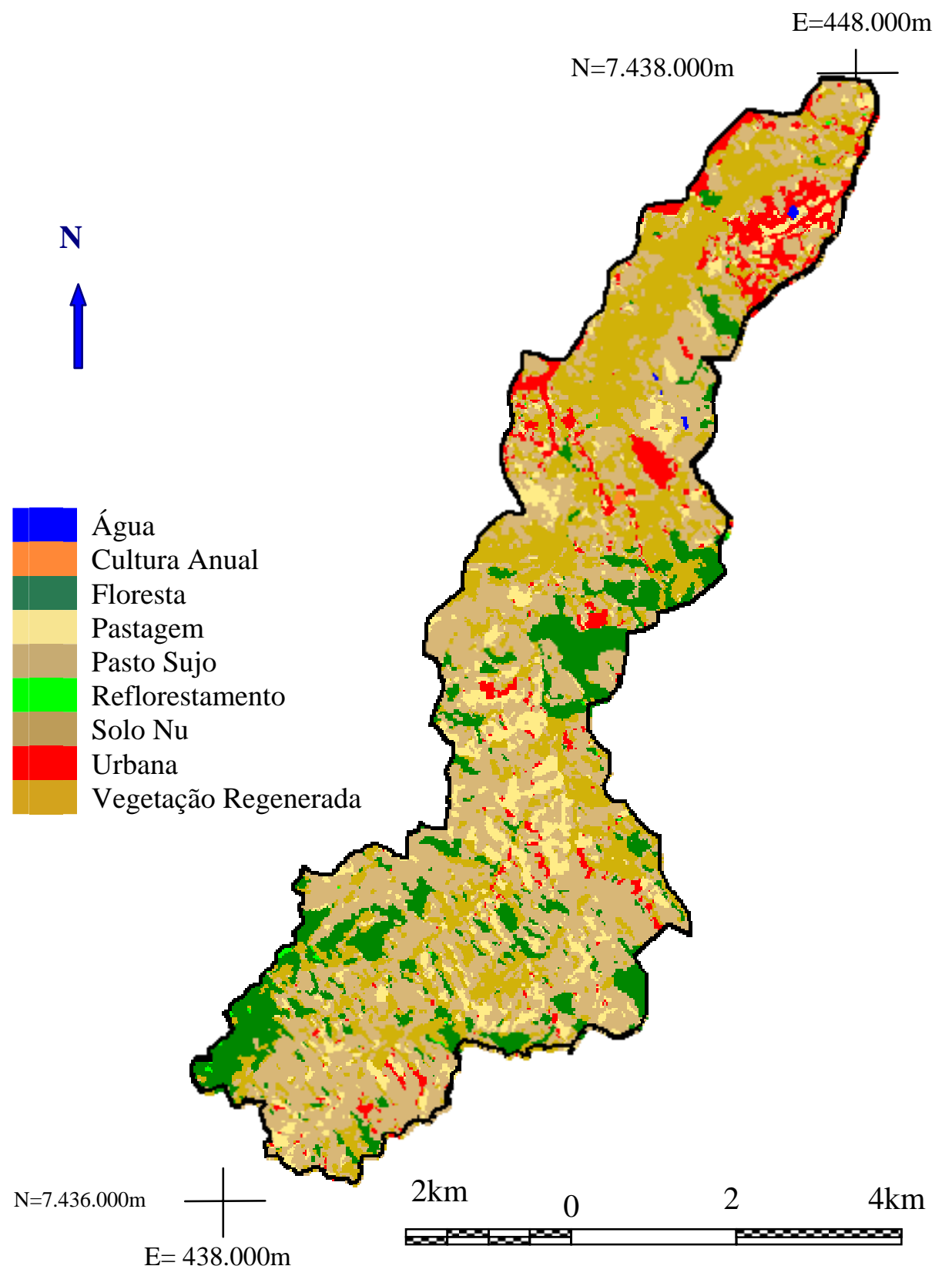

Figura 2. Classes de uso do solo na bacia hidrográfica do Ribeirão Itaim em 2003, coordenadas UTM, datum SAD 69.

Fonte: Aguiar et al. (2003).

\section{RESULTADOS E DISCUSSÃO}

A Tabela 2 apresenta a área das classes de cobertura do solo em ha e a sua porcentagem em relação a área total da bacia do Ribeirão Itaim (AGUIAR et al., 2003); resultados obtidos por meio da utilização do software SPRING no LAGEO (Laboratório de Geoprocessamento, Sensoriamento Remoto e Informática Rural do Departamento de Ciências Agrárias da Universidade de Taubaté - UNITAU). As condições hidrológicas e valores de CN para cada classe de cobertura do solo foram obtidos de Setzer e Porto (1979).

Os resultados das determinações da Velocidade de Infiltração Básica (VIB) e da Infiltração Acumulada (IAc) em áreas de pasto sujo são apresentados nas Figuras 3, 4, 5, 6 e 
7. Em geral, houve uma pequena variação nos valores de Velocidade de Infiltração, o que influenciou na duração dos testes e nos valores de Infiltração Acumulada obtidos.

Tabela 2. Classes de uso do solo, condição hidrológica adotada e os respectivos valores de CN para a bacia do Ribeirão Itaim.

\begin{tabular}{|c|c|c|c|c|c|}
\hline \multirow{2}{*}{ Classes } & \multicolumn{2}{|c|}{2003} & \multirow{2}{*}{$\begin{array}{c}\text { Condição } \\
\text { Hidrológica }\end{array}$} & \multicolumn{2}{|c|}{ CN } \\
\hline & Área (ha) & $\%$ & & Sigla & Valor \\
\hline Pasto sujo & 2.053 & 35,4 & Boa & CNps & 75 \\
\hline Pastagem & 526 & 9,1 & Ruim & $\mathrm{CNp}$ & 86 \\
\hline Floresta & 751 & 12,9 & Boa & CNf & 55 \\
\hline $\begin{array}{l}\text { Vegetação Natural em } \\
\text { Regeneração }\end{array}$ & 1.563 & 26,9 & Boa & CNvnr & 42 \\
\hline Solo $\mathrm{Nu}$ & 534 & 9,2 & Boa & CNsn & 88 \\
\hline Reflorestamento & 12 & 0,2 & Boa & $\mathrm{CNr}$ & 55 \\
\hline Urbana & 363 & 6,2 & $\begin{array}{c}65 \% \\
\text { Impermeável }\end{array}$ & $\mathrm{CNu}$ & 90 \\
\hline Cultura anual & 3 & 0,0005 & Boa & CNan & 70 \\
\hline Água & 4 & 0,1 & & & \\
\hline Área total das classes & 5.809 & 100 & & CNpond & 66,57 \\
\hline
\end{tabular}

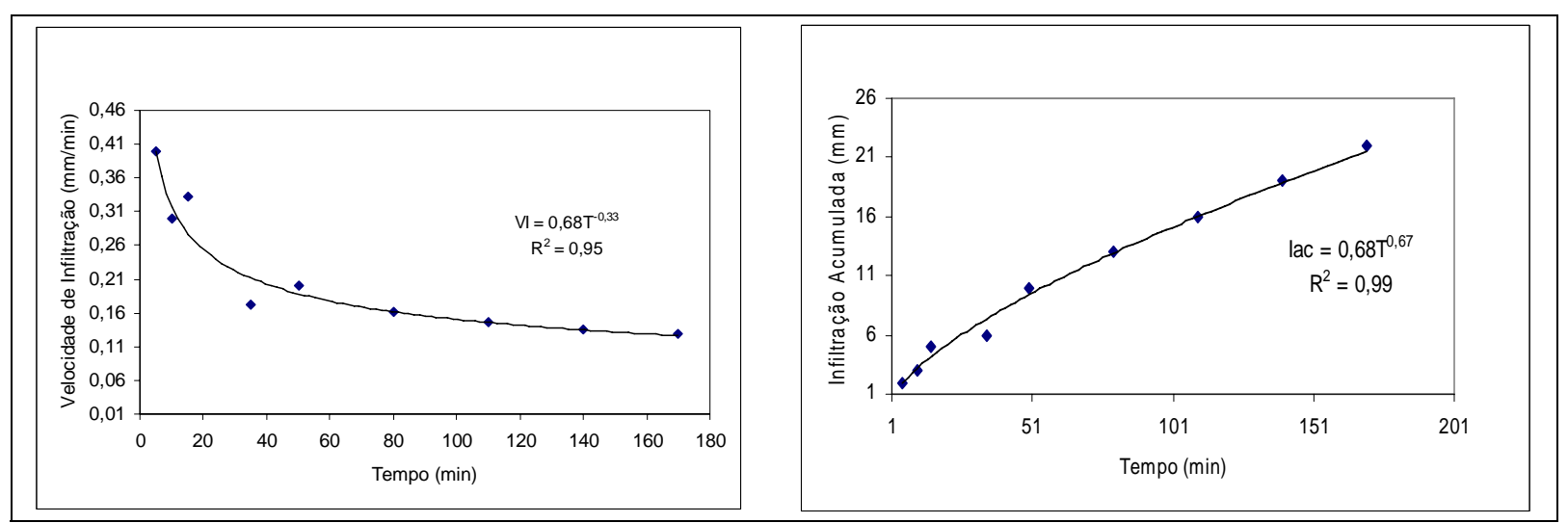

Figura 3. Velocidade de Infiltração e Infiltração Acumulada, em área com cobertura de Pasto sujo no Ponto 1.

Observa-se na Figura 3 que, por volta dos 170 minutos, a Velocidade de Infiltração tende a se estabilizar, atingindo a Velocidade de Infiltração Básica (VIB), momento em que já acumulou no solo $22 \mathrm{~mm}$ de lâmina de água.

Por outro lado, no Ponto 2, a Velocidade de Infiltração se estabilizou por volta dos 300 minutos, atingindo a Velocidade de Infiltração Básica (VIB), momento em que acumulou no solo quantidade de $22 \mathrm{~mm}$ de água (Figura 4), o que significa que o solo tornou-se saturado naquele momento.

Observa-se na Figura 5 que a Velocidade de Infiltração se estabilizou por volta dos 190 minutos, atingindo a Velocidade de Infiltração Básica (VIB) e acumulou nesse tempo uma lâmina de água de $15 \mathrm{~mm}$. 
AGUIAR, L. S. G.; TARGA, M. S.; BATISTA, G. T. Escoamento superficial na bacia hidrográfica do Ribeirão Itaim. Ambi-Agua, Taubaté, v. 2, n. 1, p. 44-56, 2007. (doi:10.4136/ambi-agua.19)
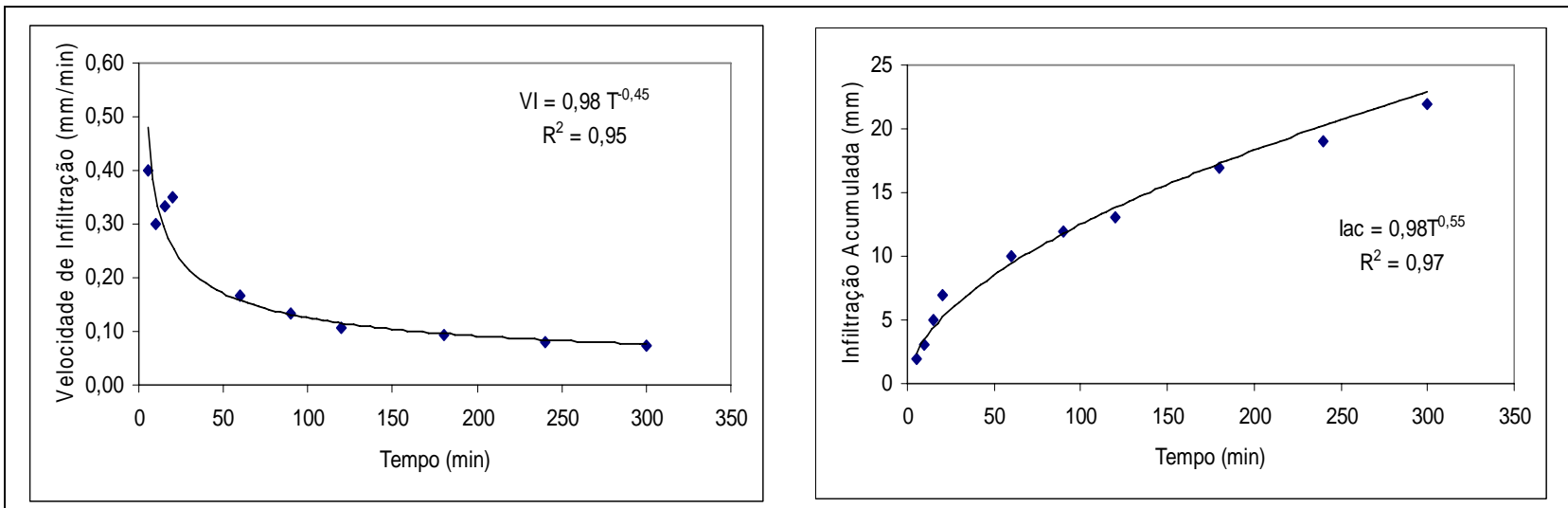

Figura 4. Velocidade de Infiltração e Infiltração Acumulada, em área com cobertura de Pasto sujo no Ponto 2.

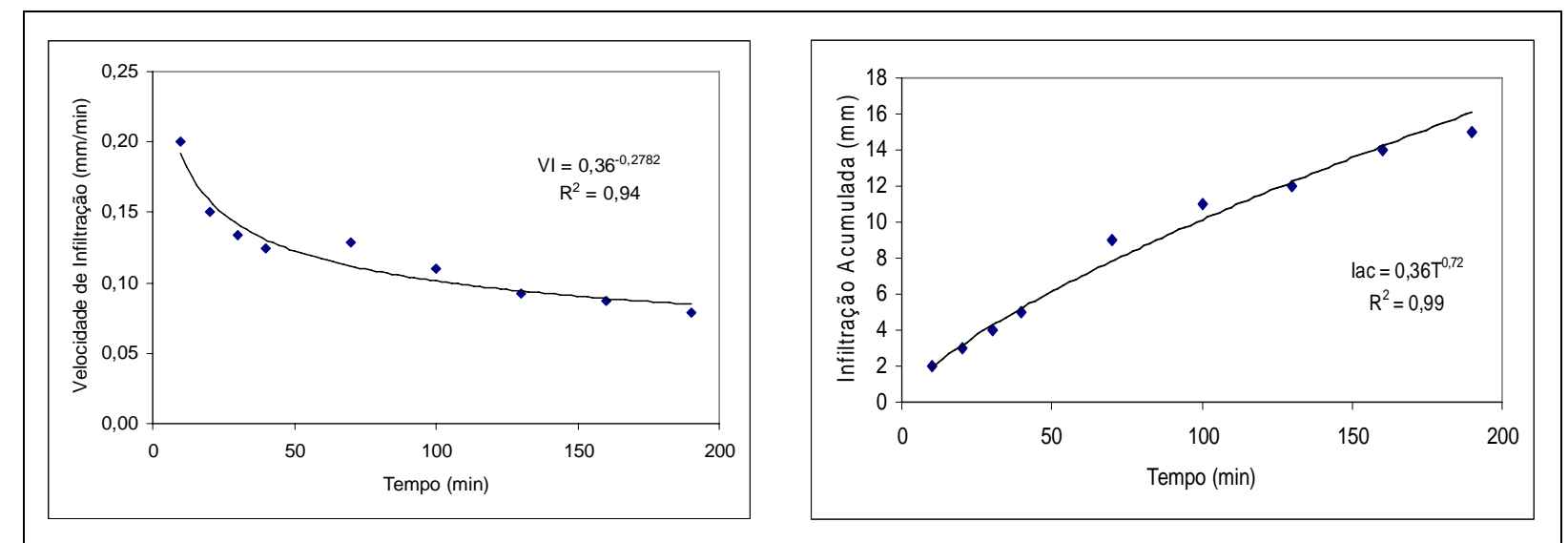

Figura 5. Velocidade de Infiltração e Infiltração Acumulada, em área com cobertura de Pasto sujo no Ponto 3.

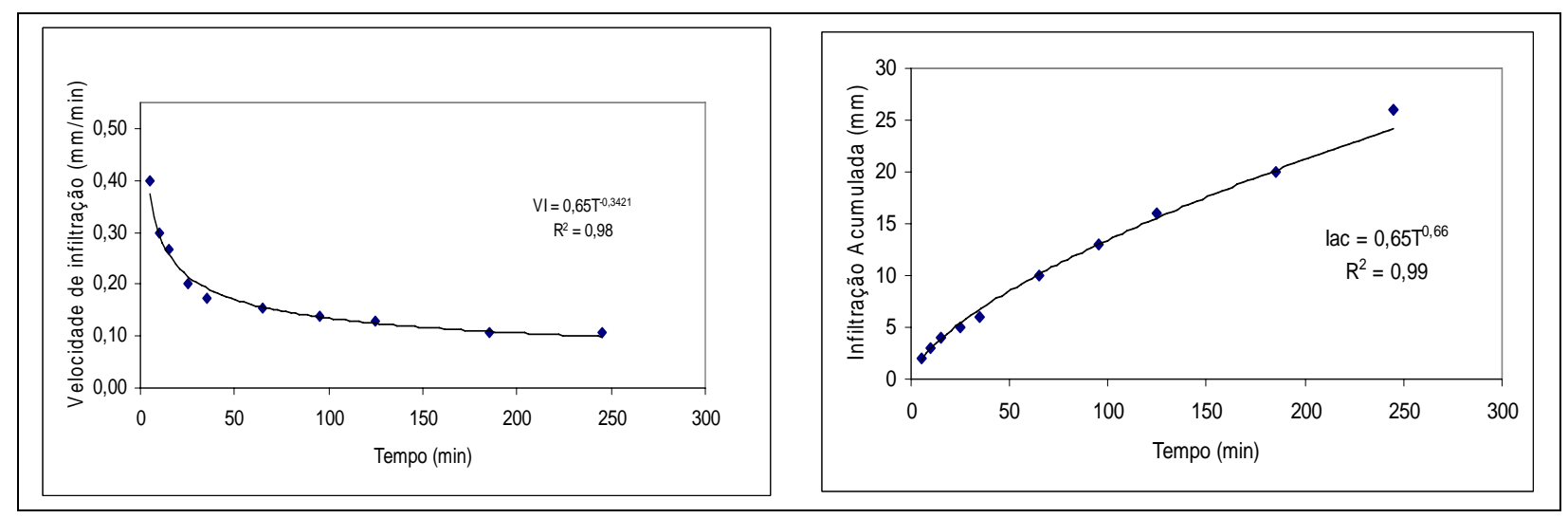

Figura 6. Velocidade de Infiltração e Infiltração Acumulada, em área com cobertura de Pasto sujo no Ponto 4.

No Ponto 4 (Figura 6), a infiltração se estabilizou aos 245 minutos, atingindo a Velocidade de Infiltração Básica (VIB), apresentando um valor de infiltração acumulada de $26 \mathrm{~mm}$.

A medida da Velocidade de Infiltração no Ponto 5 realizada na mesma classe de cobertura vegetal (pasto sujo) se estabilizou aos 240 minutos, atingindo a Velocidade de Infiltração Básica (VIB) e apresentou um valor de infiltração acumulada de 16 mm. 
Valores de densidade do solo (ds) e porosidade total (p), em duas profundidades, para cada ponto amostrado para medidas de infiltração, juntamente com os valores de Infiltração Acumulada e de Velocidade de Infiltração Básica são apresentados na Tabela 3.

Os valores de Infiltração Acumulada (IAc) e as respectivas equações obtidos dos testes de infiltração em campo encontram-se na Tabela 4.
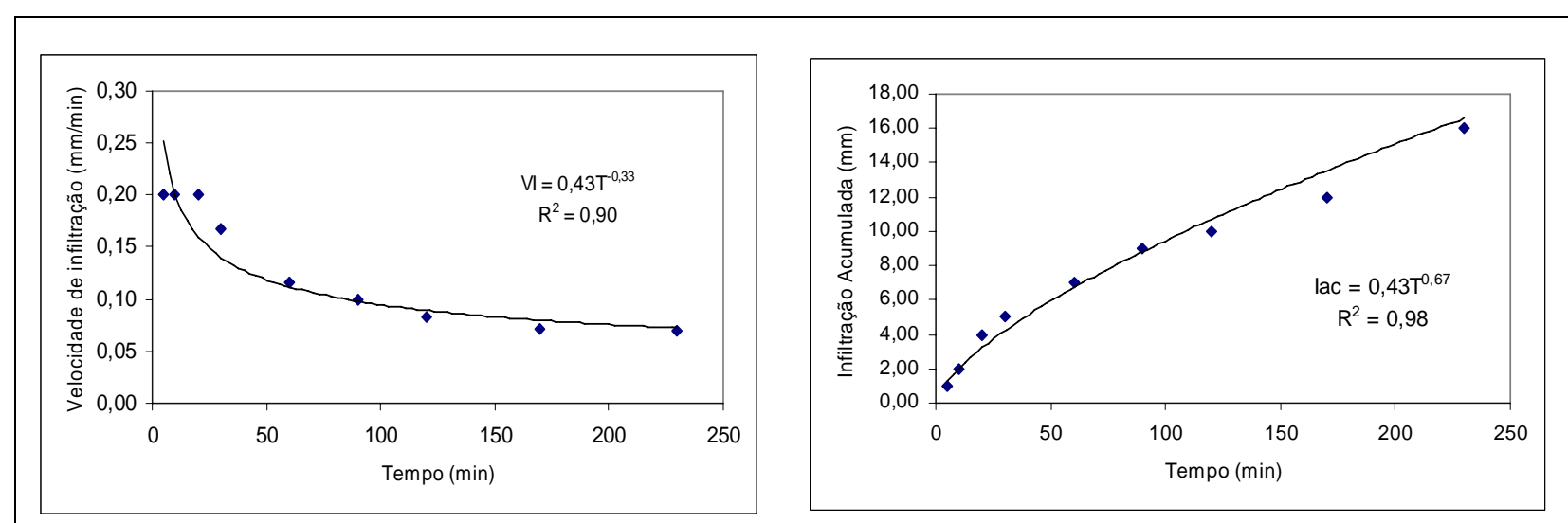

Figura 7. Velocidade de Infiltração e Infiltração Acumulada, em área com cobertura de Pasto sujo no Ponto 5.

Tabela 3. Valores de densidade do solo (ds) e porosidade total (p), Infiltração Acumulada (IAc) e Velocidade de Infiltração Básica $(\mathrm{mm} / \mathrm{h})$ para cada ponto de teste de infiltração.

\begin{tabular}{|c|c|c|c|c|c|c|}
\hline $\begin{array}{c}\text { Uso e } \\
\text { Cobertura }\end{array}$ & \multicolumn{2}{|c|}{$0-20 \mathrm{~cm}$} & \multicolumn{2}{|c|}{$20-40 \mathrm{~cm}$} & \multicolumn{2}{|c|}{$0-40 \mathrm{~cm}$} \\
\hline Pasto Sujo & $\begin{array}{c}\text { ds } \\
\left(\mathrm{g} / \mathrm{cm}^{3}\right. \\
\quad)\end{array}$ & $\begin{array}{c}\mathbf{p} \\
(\%)\end{array}$ & $\begin{array}{c}\text { ds } \\
\left(\mathrm{g} / \mathrm{cm}^{3}\right)\end{array}$ & $\begin{array}{c}\mathbf{p} \\
(\%)\end{array}$ & $\begin{array}{c}\text { IAc } \\
(\mathbf{m m})\end{array}$ & $\begin{array}{c}\text { VIB } \\
(\mathrm{mm} / \mathrm{h} \\
)\end{array}$ \\
\hline 1 & 1,47 & 47,31 & 1,50 & 48,78 & 22 & 7,8 \\
\hline 2 & 1,40 & 49,94 & 1,52 & 44,84 & 22 & 4,2 \\
\hline 3 & 1,55 & 40,21 & 1,63 & 40,15 & 15 & 4,8 \\
\hline 4 & 1,40 & 47,19 & 1,58 & 43,09 & 26 & 6,6 \\
\hline 5 & 1,42 & 49,39 & 1,56 & 45,25 & 16 & 4,2 \\
\hline Média & 1,45 & 46,81 & 1,56 & 44,42 & 20 & 5,5 \\
\hline
\end{tabular}

Fonte: Aguiar (2003).

Considerando a classificação de Reichardt (1987), os valores de Velocidade de Infiltração Básica (VIB) obtidos neste trabalho (Tabela 3) demonstram que o solo apresenta de baixa a média capacidade de infiltração. A velocidade de infiltração reflete as condições físicas do solo, tais como sua estrutura, porosidade, densidade, bem como a presença ou ausência de camadas compactadas de solo. Dessa forma, deduz-se, para o solo em questão, que os valores elevados de densidade do solo e baixa porosidade total para as profundidades de 0-20 e 20-40 (Tabela 3) estão influenciando a infiltração de água no solo, o que corrobora os resultados obtidos por Centurion et al. (2001). A baixa velocidade de infiltração promove maior escoamento de água na bacia, maior erosão e se constitui em um fator importante na taxa de sedimentação do ribeirão Itaim, que, em sua vazão média de $2.146 \mathrm{~m}^{3} / \mathrm{h}$, apresentou uma vazão sólida de 6.848 kg/dia (Moreira, 2005). 
Tabela 4. Equações de Infiltração Acumulada e valores da Infiltração Acumulada (IAc) obtidos nos testes de campo para o tempo de duração da chuva igual ao tempo de concentração.

\begin{tabular}{cccc}
\hline $\begin{array}{c}\text { Uso e } \\
\text { Cobertura } \\
\text { do Solo } \\
\text { (Pasto Sujo) }\end{array}$ & $\begin{array}{c}\text { Tempo de } \\
\text { Concentração } \\
\text { [min] }\end{array}$ & $\begin{array}{c}\text { Equação de Infiltração } \\
\text { Acumulada }\end{array}$ & $\begin{array}{c}\text { Infiltração } \\
\text { Acumulada } \\
\text { [mm] }\end{array}$ \\
\hline $\mathbf{1}$ & 180 & IAc $=0,68 \times 180^{0,67}$ & 22,32 \\
$\mathbf{2}$ & 180 & IAc $=0,98 \times 180^{0,55}$ & 17,27 \\
$\mathbf{3}$ & 180 & IAc $=0,36 \times 180^{0,72}$ & 15,47 \\
$\mathbf{4}$ & 180 & IAc $=0,65 \times 180^{0,66}$ & 19,79 \\
$\mathbf{5}$ & 180 & IAc $=0,42 \times 180^{0,67}$ & 14,06 \\
\hline
\end{tabular}

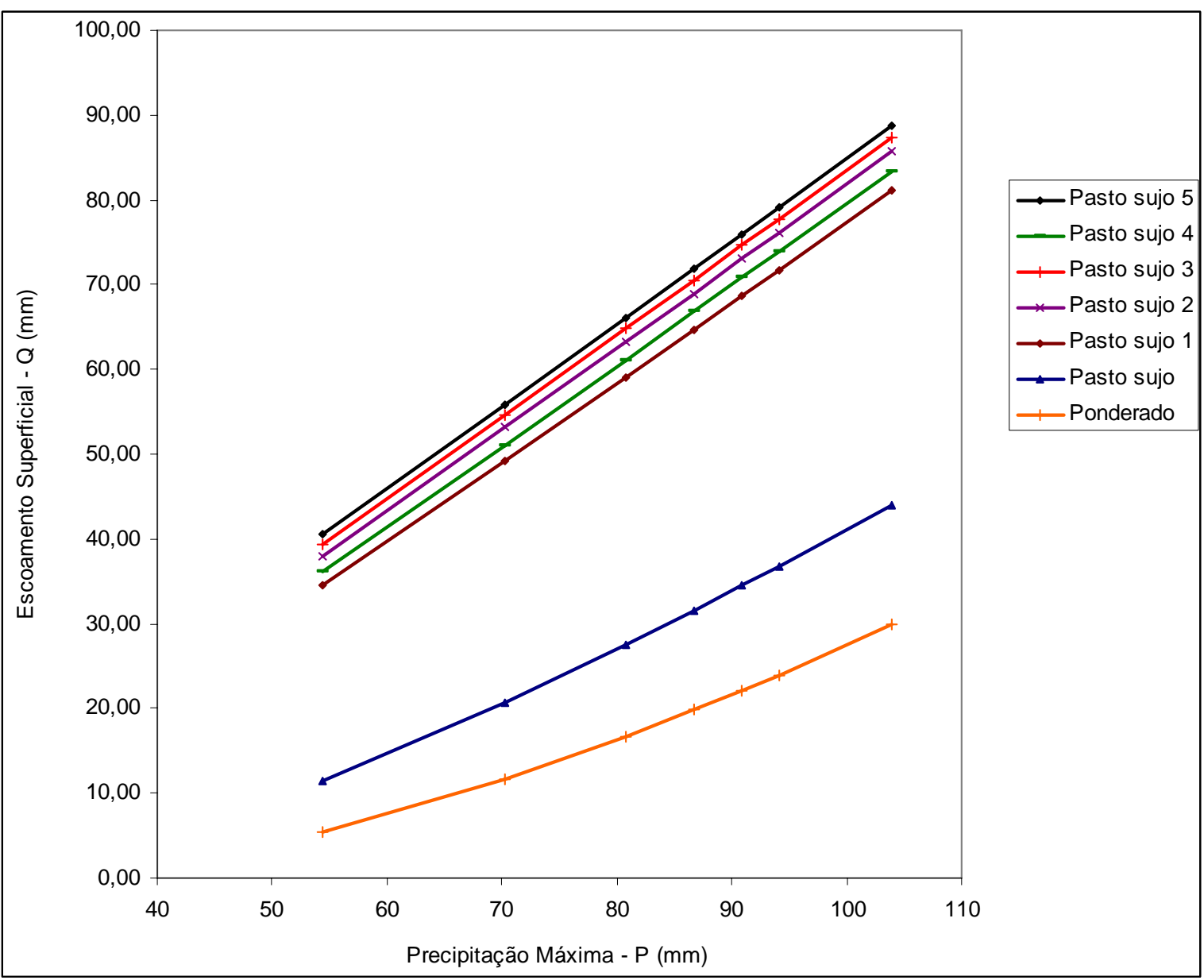

Figura 8. Variação do Escoamento Superficial em função da Precipitação Máxima na bacia do Ribeirão Itaim.

Em geral, o escoamento superficial aumentou à medida que aumentou a precipitação máxima (Figura 8). O aumento foi mais acentuado quando se utilizaram dados de infiltração potencial levantados no campo (Método 1; Figura 8, Pasto sujo). Os valores de infiltração potencial foram $\mathrm{S}=84,7 \mathrm{~mm}$ e $\mathrm{S}=127 \mathrm{~mm}$, respectivamente, quando se considerou a 
cobertura vegetal pasto sujo com $\mathrm{CN}=75$ para toda a bacia (Método 2) e quando se utilizou o valor de CN ponderado (Método 3), que levou em consideração a área de cada classe de uso e cobertura do solo (CNpond $=66,57$ ). Pelo valor de CNpond menor, observa-se que, ao se assumir um único tipo de cobertura para a bacia, superestima-se o valor de infiltração e, em conseqüência, subestima-se o escoamento.

Pode-se com isso inferir que o método Curva-Número aplicado com base em valores de CN (Setzer e Porto, 1979) subestimou o escoamento superficial na bacia do Ribeirão do Itaim e, portanto, esse método não pode ser aplicado de forma generalizada, sem que se obtenham medidas em campo de infiltração de água no solo para se promover ajustes para situações locais.

\section{CONCLUSÕES}

As metodologias adotadas para o cálculo da taxa de infiltração de água permitiram a estimativa do escoamento superficial da bacia de forma consistente para diversos valores de precipitações máximas (54,4; 70,3; 80,8; 86,7; 90,9; 94,1 e 103,9 mm) para o tempo de duração de 3 horas e para os tempos de retorno de 2, 5, 10, 15, 25, 50 e 100 anos. Entretanto, os valores das estimativas do escoamento superficial variaram substancialmente em função do método utilizado (infiltrômetro em campo vs. CN) e em função do uso e cobertura do solo (CN tradicional vs. CN ponderado).

Os valores de escoamento superficial obtidos pelo Curva-Número tanto convencional (cultura predominante) quanto ponderado (levando-se em consideração todas as classes de uso e cobertura do solo) apresentaram-se mais baixos que os estimados com base em medidas de infiltração de água no solo, obtidos em campo, com anéis concêntricos, para os diversos valores de precipitação e tempos de retorno associados.

\section{REFERENCIAS}

AGUIAR, L. S. G. Estimativa do escoamento superficial a partir de testes da infiltração potencial na Bacia do Ribeirão Itaim, Taubaté - SP. 2004. 104f. Dissertação (Mestrado em Ciências Ambientais) - Departamento de Ciências Agrárias, Universidade de Taubaté, Taubaté, 2004.

AGUIAR, L. S. G.; BATISTA, G. T.; MONTESI, E. C.; PEREIRA, W. F. Dinâmica do uso e ocupação do solo na microbacia do ribeirão Itaim utilizando dados de sensoriamento remoto e SIG. In: ENCONTRO DE INICIAÇÃO CIENTÍFICA, 8., 2003; MOSTRA DE PÓS-GRADUAÇÃO, 4., 2003, Taubaté. Resumo... Taubaté: Universidade de Taubaté, 2003. p. 255.

BERNARDO, S. Manual de irrigação. 2. ed. Viçosa: Imprensa Universitária, 1982. 463p.

BRAGA JUNIOR, B. P.; CONEJO, J. G. L. Simulação digital do ciclo hidrológico através do "Stanford Watershed Model IV". In: Hidrologia dinâmica: curso de engenharia hidrológica. São Paulo: EPUSP/DAEE/ABRH, 1983. p. B1-B23. vol. 1.

CENTURION, F. J.; CARDOSO J. P.; NATALI, W. Efeitos de formas de manejo em algumas propriedades físicas e químicas de um latossolo vermelho em diferentes agroecossistemas. Revista Brasileira de Engenharia Agrícola e Ambiental, Campina Grande, v. 5, n. 2, p. 254-258, 2001. 
DIAMOND, J.; SHANLEY, T. Infiltration rate assessment of some major soils. Irish Geography, Dublin, v. 36, n. 1, p. 32-46, 2003.

EMPRESA BRASILEIRA DE PESQUISA AGROPECUÁRIA. Serviço Nacional de Levantamento e Conservação dos Solos. Manual de métodos de análise de solo. 2.ed. Rio de Janeiro: Ministério da Agricultura, 1997. 212 p.

FISCH, G. Distribuição da Precipitação em Taubaté, Vale do Paraíba (SP). Revista Biociências, Taubaté, v. 5, n. 2, p. 7-11, 1999.

GROVE, M.; HARBOR, J.; ENGEL, B. Composite vs. distributed curve numbers: effects on estimates of storm runoff depth. Journal of the American Water Resources Association, Middleburg, v. 34, n. 5, p. 1015-1023, 1998.

JACOBS, J. H.; SRINIVASAN R. Effects of curve number modification on runoff estimation using WSR-88D rainfall data in Texas watersheds. Journal of soil and water conservation, Ankeny, v. 60, n. 5, p. 274-275, 2005.

MACHADO, R. E. Simulação de escoamento de produção de sedimentos em uma microbacia hidrográfica utilizando técnicas de modelagem e geoprocessamento. 2002. 154 f. Tese (Doutorado em Agronomia) - Escola Superior de Agricultura, Universidade de São Paulo, Piracicaba, 2002.

MAHESHAWARI, B. L. Development of an automated double ring infiltrometer. Australian Journal of Soil Research, Collingwood, v. 34, p. 709-714, 1996.

MARTINEZ JR. F.; MAGNI, N. L. G. Equações de chuvas intensas do Estado de São Paulo. In: SÃO PAULO (Estado). Secretaria de Recursos Hídricos, Saneamento e Obras. Departamento de Águas e Energia Elétrica. Centro Tecnológico de Hidráulica e Recursos Hídricos. São Paulo: Escola Politécnica da Universidade de São Paulo, 1999, 125p. Disponível em: <http://www.sigrh.sp.gov.br/sigrh/basecon/ecisp/index.htm>. Acesso em 6 maio 2005.

MOREIRA, D. W. Intensidades máximas de chuvas e sua influência na vazão máxima e sedimentação do Ribeirão Itaim, Taubaté - SP. 2005. 160f. Tese (Doutorado em Ciências Ambientais) - Universidade de Taubaté, Taubaté, 2005.

NATIONAL RESOURCES CONSERVATION SERVICE. Estimation of direct runoff from storm raifall. In: Hydrology: national engineering handbooks. Washington: USDA, 1997. 79 p. part 630. cap. 10. Disponível em: <www.ftw.nrcs.usda.gov>. Acesso em abril 2007.

REICHARDT, K. A água em sistemas agrícolas. São Paulo: Manole, 1987. 186 p.

ROCHA, J. V. El Sistema de Informaciones Geográficas (SIG) en los Contextos de Planificación del Medio Físico y de las Cuencas Hidrográficas. In: REPETTO, F.L.; KAREZ, C. S. Aspectos geológicos de protección ambiental. Montevidéu: UNESCO, 2000. p. 112-123.

SBRUZZI, R. S. Metodologia para verificação da adequação do uso da terra na bacia do Ribeirão Itaim, afluente do rio Una, Taubaté, SP. 2004. 75 f. Dissertação (Mestrado em Ciências Ambientais) - Departamento de Ciências Agrárias, Universidade de Taubaté, Taubaté, 2004. 
SECCO, D. et al. Atributos físicos e produtividade de culturas em um latossolo vermelho argiloso sob diferentes sistemas de manejo. Revista Brasileira de Ciência do Solo, Campinas, v. 29, n. 3, p. 407-414, 2005.

SETZER, J.; PORTO, R. L. L. Tentativa de avaliação do escoamento superficial de acordo com o solo e seu recobrimento vegetal, nas condições do estado de São Paulo. Boletim Técnico DAEE, São Paulo, v. 2, n. 2, p. 81-104, 1979.

SMEMOE, C. M.; NELSON, E. J.; ZHAO, B. Spatial averaging of land use and soil properties to develop the physically-based Green and Ampt parameters for HEC-1. Environmental Modelling \& Software, [S.l.], v. 19, n. 6, p. 525-535, 2004.

TRIPATHI, M. P.; PANDA, R. K.; RAGHUWANSHI, N. S. Identification and prioritization of critical sub-watersheds for soil conservation management using the Swat Model. Biosyst. Eng., London,v.85, n.3, p.365-379, 2003.

WENDLAND, W. M. Temporal responses of surface-water and ground-water to precipitation in Illinois. Journal of the American Water Resources Association, Middleburg, v. 37, n. 3, p. 685-693, 2001. 